\title{
Left and right heart haemodynamics during spontaneous angina
}

Sir:

In the past it has been shown that spontaneous angina pectoris associated with electrocardiographic ST segment depression is preceded by a rise in systemic and pulmonary artery pressures in 86 per cent of cases (Roughgarden, 1966).

Recently Guazzi et al. (1975, British Heart fournal, 37, 401) showed that no circulatory change was responsible for eliciting spontaneous angina pectoris with ST depression. They found that a fall in arterial pressure and a rise in pulmonary wedge pressure occurred initially, but these were followed by a secondary hypertensive phase during the attack of angina pectoris.

The increased work of the heart caused by a rise in arterial pressure and heart rate is generally considered to be the cause of ischaemia during exercise in patients with clinical angina pectoris.

Roughgarden concluded that the pressure changes of exertional angina resembled those occurring before spontaneous angina. The two authors mentioned seem to have conflicting conclusions for the mechanism of spontaneous angina pectoris.

$$
\begin{aligned}
& \text { John M. Bete, } \\
& \text { Cape Cod Medical Center, } \\
& \text { Hyannis, Massachusetts, } \\
& \text { U.S.A. }
\end{aligned}
$$

\section{Reference}

Roughgarden J. W. (1966). Circulatory changes associated with spontaneous angina pectoris. American fournal of Medicine, 41, 947.

This letter was shown to Dr. Guazzi who comments as follows:

The discrepancy which Dr. Bete has noticed between Roughgarden's data and ours is more apparent than real. Dr. Bete probably refers to the summary of Roughgarden's paper when he writes that this author has shown that spontaneous angina pectoris associated with $S T$ segment depression is preceded by a rise in systemic and pulmonary artery pressures in 86 per cent of cases, concluding that the pressure changes during exertional angina resemble those before spontaneous angina. Actually, Roughgarden reported that pressure rise in the greater and lesser circulation precedes the onset of anginal pain in 86 per cent of the cases, but the point is that anginal pain and electrocardiographic signs of ischaemia are not synonymous. Myocardial ischaemia and anginal pain (Guazzi et al., 1976), indeed, are two separate phenomena; anginal pain does not necessarily accompany the ischaemia and, when present, never precedes it. In our paper the reference point for the evaluation of the circulatory variations was the onset of the ST segment displacement and not the onset of pain. We have pointed out that no circulatory change, either systemic or pulmonary, precedes the ST segment depression; this led us to conclude that spontaneous myocardial ischaemia is not the result of increased work of the heart.

If Roughgarden's findings are compared with ours with this point in mind, the discrepancy becomes smaller. She found that in only 7 out of 21 monitored episodes of myocardial ischaemia (30\% of cases) blood pressure changes preceded the ST segment depression. In these cases, however, the relation of the magnitude and the time of onset of the pressure variations to the electrocardiographic abnormalities was not reported; it is, therefore, difficult to evaluate their significance in producing ischaemia.

$$
\begin{aligned}
& \text { Maurizio Guazzi, } \\
& \text { Istituto di Ricerche Cardiovascolari } \\
& \text { dell' Università di Milano, } \\
& \text { Milan, Italy. }
\end{aligned}
$$

\section{Reference}

Guazzi, M., Olivari, M. T., Polese, A., Fiorentini, C., and Magrini, F. (1976). Repetitive myocardial ischemia of Prinzmetal type without angina pectoris. Americ:n fournal of Cardiology, 37, 923. 